\title{
Orientação de Estágio: uma experiência na formação de docentes
}

Supervision Stage: an experiment in teachers training

\author{
Karla Marques da Rocha* \\ Universidade Federal de Santa Maria \\ Ilse Abegg** \\ Universidade Federal de Santa Maria \\ Eliana Rela*** \\ Universidade de Caxias do Sul
}

Resumo Este artigo aborda a utilização das Tecnologias Educacionais em Rede, especialmente o recurso Wiki, na disciplina de Supervisão de Estágio em um Programa Especial de Graduação de Formação de Professores para a Educação Profissional e Tecnológica, em uma universidade pública brasileira. Analisou-se os registros feitos por vinte e nove estudantes e o respectivo orientador, referentes aos planos de Aula e sua implementação como parte do processo da avaliação das competências do planejar e do refletir. As postagens geraram reflexões no espaço Wiki, proporcionando categorias de elementos indicadores para a supervisão dos futuros estágios, na forma de rede de conversação. A possibilidade de acompanhamentos, orientações, avaliações e aprendizagens tornouse efetivamente um período de construção de experiências, além do espaço acadêmico.

PalaVRas-chaVe: Formação de Professores, Supervisão de Estágio, Tecnologias Educacionais em Rede.

\begin{abstract}
This paper discusses the use of Web-based Educational Technologies, specially the Wiki activity tool in Moodle, on the subject of Supervised Teacher Training of the Special Undergraduate Program of Teachers' Education for Professional and Technological Education of UFSM. The posts made by 29 students and their advisor were analyzed with regards to their teaching lessons and their implementation. The posts enabled a discussion on the Wiki space fostering categories of indicative elements for the supervision for future training by means of conversation networks. The possibility of follow-up, guiding, evaluations and learning became effectively a period of constructing experiences, beyond the academic space.
\end{abstract}

KEYWORDS: Teacher Education, Supervision Stage, Educational Technology Network. 


\section{Introdução}

No atual momento do processo de formação de professores, nos cursos de licenciatura, uma significativa atenção tem sido dada as propostas de professores reflexivos. Essa proposta, aceita com simpatia por boa parte dos educadores, parte do trabalho de Schön (1992), que propõe que o pensamento reflexivo do professor(a), no enfrentamento das situações divergentes da prática, se desenvolve na competência de refletir sobre a ação, criando uma nova realidade, experimentando, corrigindo e inventando, através do diálogo que estabelece com essa mesma realidade. A reflexão é, portanto, base para o desenvolvimento do profissional e, em se constituindo numa espiral formativa, retorna a reflexão sobre a reflexão na ação (SILVA, 2002). O que nos permite pensar na valorização da prática profissional como momento de construção de conhecimento por meio da reflexão, análise e problematização dessa prática e a consideração do conhecimento tácito, presente nas soluções que os profissionais encontram na ação docente. Através da prática refletida, é possível responder com situações novas às situações de incerteza e indefinição que transitam os caminhos da profissão docente (RELA et. al., 2006).

Segundo Pimenta e Lima (2010), o estágio curricular supervisionado tem a finalidade de integrar o processo de formação do aluno, de modo a considerar o campo de atuação como objeto de análise, de investigação e de interpretação crítica, a partir dos nexos com as disciplinas do curso. Por ser um campo de conhecimento, volta-se a uma visão ampla, em que um processo didático-pedagógico, intencional, possibilita a formação crítica do educador (Professor) a partir da articulação teoria-prática, por meio de intervenções contextualizadas de caráter emancipatório. Nesse sentido, a intervenção dos atores da atividade de estágio deve estar caracterizada por um tempo de formação, que deve ocorrer no mundo real do trabalho, sendo um componente curricular que é orientado por um docente. Este atua no sentido de considerar o estágio como um momento de ação e reflexão, ou seja, um eixo articulador do curso.

Entende-se que a ação formativa, proposta para o estágio, precisa estar voltada ao desenvolvimento de competências estratégicas, a fim de promover a dimensão do pensamento crítico-reflexivo dos atores sociais sobre os processos em que estão envolvidos. Nessa dimensão, a avaliação se apresenta como estratégia do aprender a aprender. $\mathrm{O}$ objeto da formação de docentes se expressa, então, em termos de competências e não simplesmente de conhecimentos. Essa mudança de perspectiva pressupõe uma visão que integra saberes com uma visão de prática, entendida como a expressão situada de competências. Desse quadro é que se propõe a atenção estratégica sobre modelos da ação focados sobre a experiência. A avaliação de competências não pode coincidir com a prática, ainda difundida, que requer uma reprodução do conhecimento. Aqui se propõem modelos de avaliação, caracterizados por processos de decisão compartilhados e orientados, afim de oportunizar a construção e operacionalização dos saberes. (ALBERICI, 2008, p. 134).

Um processo avaliativo pode ser planejado de forma a permitir que a rede de atores envolvidos, na avaliação, reveja o processo percorrido pelo estudante, desde o início de um módulo, disciplina ou unidade de estudo cursada, perpassando, desta 
forma, com o desenvolvimento da aprendizagem e possíveis contextualizações sobre os apontamentos, para estudos e reconstrução de conhecimento.

A estruturação básica da avaliação do estágio privilegia a articulação entre as ações docentes cotidianas, desenvolvidas pelos alunos e mediadas pelo(s) orientador(es), caracterizando os processos intersubjetivos, sustentados por premissas reflexivas. O espaço do encontro entre ambos é a ferramenta de produção colaborativa wiki, incorporada como recurso de atividade no ambiente virtual de ensino-aprendizagem Moodle, que é mediador tecnológico destas ações educativas.

Com base nesses pressupostos e reflexões, procurou-se desenvolver um estudo, de natureza qualitativa, envolvendo a análise do conteúdo das postagens e orientações referente aos planos de aula e sua implementação, na ferramenta wiki, de uma disciplina presencial. Acredita-se que a construção do conhecimento e mudanças de conduta, a partir das reflexões das próprias ações, em um espaço tecnológico, possa contribuir para a orientação do estágio supervisionado, na medida em que o recurso pode proporcionar um espaço de conversa, interação e análise da prática do futuro docente. Procurou-se, a partir deste enfoque, estruturar o texto em três etapas, que, apesar de estarem hierarquicamente listadas, se entrelaçam em todos os momentos desta reflexão sobre a reflexão na ação. Portanto, buscou-se:

1 - Abordar a ferramenta de atividade wiki do Moodle, como um recurso tecnológico possível de ser utilizado nas atividades de orientação de estágio supervisionado de ensino, nos cursos de licenciatura, no caso, o Programa Especial de Graduação de Formação de Professores para a Educação Profissional e Tecnológica, da UFSM;

2 - Analisar as possibilidades da ferramenta wiki, como espaço de diálogo, interação e reflexão do aluno estagiário e seu orientador;

3 - Analisar as contribuições desses diálogos, interações e reflexões, mediadas pela ferramenta wiki, como possibilitadores, também, para avaliação no processo de formação do professor reflexivo, da Educação Profissional.

\section{Wiki: um espaço para ação-reflexão-ação em rede}

Como animais linguajantes, existimos na linguagem, mas como seres humanos existimos (trazemos nós mesmos à mão em nossas distinções) no fluir de nossas conversações, e todas as nossas atividades acontecem como diferentes espécies de conversação. (VIEIRA, 2004).

Segundo o autor, é na conversação que ocorre a coordenação consensual de ações. Para Maturana (2002), coordenações consensuais são as interações na linguagem, ou seja, a linguagem é considerada como um espaço construído por ações, que se tornam comuns e, por isso, consensuais. Já a palavra "conversar", segundo Maturana (2002), vem da união de duas raízes latinas: cum, que quer dizer "com", e versare que quer dizer "dar voltas com" o outro. Então, ao conversarmos "damos voltas juntos", ou seja, entramos em um consenso recursivo de informações que pode ser estabelecido 
em diferentes espaços educativos de convivência, como por exemplo, em um Ambiente Virtual de Ensino e Aprendizagem (AVEA). Por meio deste e mediados por um recurso tecnológico, é possível a relação entre o real aparente, visível, perceptível e o concreto, pensado na elaboração da compreensão do que está sendo vivido.

Isso significa dizer que é no diálogo com o outro que construímos as reflexões que nos levam ao desenvolvimento psico-intelectual necessário à formação profissional. Para Freire (1986), o diálogo é uma conduta necessária, na medida em que os seres humanos se transformam, cada vez mais, em seres humanos criticamente comunicativos. É um momento em que se encontram para refletir sua realidade, tal como a fazem e re-fazem. Tradicionalmente, as orientações das atividades de Estágios Supervisionados de Ensino vem sendo desenvolvidas, em sua maioria, de forma presencial, sem utilização das Tecnologias de Informação e Comunicação (TIC), via rede de computadores, limitando, assim, os momentos de comunicação, ou seja, da conversação. Em pesquisas recentes (ABEGG, 2013), constatou-se que isso ocorre por vários motivos, dentre eles, pela falta de conhecimento e fluência nas ferramentas tecnológicas-educacionais para mediar essas ações. Isso limita a interação orientador-estagiários, pois exige-se a presença física de ambos, em tempos e locais determinados, para o desenvolvimento do diálogo em torno das questões que envolvem a ação docente orientada. Esse modelo face-a-face de comunicação circunscreve o estudante-estagiário ao espaço físico da universidade ao qual pertence e, dessa forma, reduz os campos de atuação deste profissional em formação. $\mathrm{O}$ que limita também a possibilidade de contribuir para o desenvolvimento e atualização curricular das instituições escolares, de educação básica, mais distantes das instituições formadoras.

Neste contexto, as ferramentas de colaboração via web, em ambientes de produção escolar colaborativa (como wiki do Moodle), tornam-se um processo inovador e potencializador dos saberes necessários à prática docente. Em 2007, Tapscott \& Williams escreveram: "daqui a cinco anos, a capacidade de usar Wikis será uma competência profissional exigida” (TAPSCOTT \& WILLIAMS, 2007, p. 308). Passado este tempo, percebe-se que realmente as ferramentas de colaboração em ambientes virtuais, como a wiki do Moodle, no âmbito escolar, já se tornaram imprescindíveis para transformar o modo produtivo de estudantes e professores. Incorporados em AVEA podem transformarem-se em espaços para ação-reflexão-ação em rede, ampliando espaços de conversação entre professores orientadores e estagiários. Com a mediação das atividades de orientações de estágio supervisionado de ensino com a ferramenta wiki, transforma-se o campo de estágio de ensino em objeto de análise constante, potencializando investigações na e sobre a prática docente cotidiana. Assim, os momentos de reflexão possibilitam uma interpretação crítica das ações de estágio supervisionado, contribuindo de forma significativa para a formação do professor da educação profissional. Nesse contexto, a mediação e o feedback,, promovidos pelo orientador, se constituem no próprio processo avaliativo, o qual assume um valor que não se limita a medidas de níveis de aprendizagem disciplinares ou à eficiência na execução de uma performance profissional, mas se configura como um processo de investigação sobre a experiência do sujeito, a fim de promover níveis sempre maiores de consciência, sobre suas capacidades cognitivas, afetivas e sociais. 
Alberici (2008, p. 132) registra que a avaliação representa um aspecto constitutivo e estrutural para o funcionamento dos sistemas complexos nos cenários globais da atualidade. $\mathrm{O}$ encontro com a experiência, no contexto da pesquisa em questão, dá-se quando os alunos estagiários produzem e publicam sínteses reflexivas sobre suas atuações docentes durante o estágio, nas wikis, e o professor orientador acessa, interpreta e promove feedback, a fim de construir os sentidos das ações.

\section{Especificidades metodológicas}

Este trabalho, classificado como uma pesquisa qualitativa, contempla a análise de conteúdo dos planos de aula e sua implementação, em duas turmas de Estágio Supervisionado III, do Programa Especial de Graduação (PEG) de Formação de Professores para a Educação Profissional, na modalidade presencial. Este programa referese a uma proposta de formação pedagógica para os profissionais que atuam, ou pretendem atuar, como professores na Educação Profissional Técnica de Nível Médio, nas respectivas áreas de formação. Isto significa que os alunos ingressantes são oriundos de diversos cursos de formação, que compreendem sete eixos tecnológicos, entre eles Controle e Processos Industriais; Recursos Naturais; Produção Alimentícia; Gestão e Negócios; Informação e Comunicação; Ambiente, Saúde e Segurança; Infraestrutura. Por possuírem a formação técnica (de bacharéis), atualmente, em muitos casos, almejam e ou necessitam a formação pedagógica para lecionar nas suas respectivas áreas.

A criação deste curso decorre, ainda, da necessidade firmada na Lei de Diretrizes e Bases da Educação Nacional (Lei 9.394/96) de que a formação dos professores para atuar na Educação Básica far-se-á em nível superior, em curso de licenciatura, de graduação plena, conforme o Artigo 62. Neste sentido, o PEG vem atender essa demanda de formação de professores para a Educação Profissional.

Constituído por três semestres, procura inserir o estudante na escola, desde o primeiro momento, especialmente, através dos Estágios Supervisionados I - enfatizando a observação como objetivo central, correspondendo a 105 horas; Estágio Supervisionado II - detendo-se nos Planejamentos de Ensino (105 horas); e a docência orientada, no III, que corresponde a trinta (30) horas de aula, ministradas no último semestre da formação e sob a supervisão de dois orientadores: o professor regente da disciplina do curso técnico da escola concedente e o professor orientador da instituição proponente, no caso, a Universidade Federal de Santa Maria. Este, também com carga horária de 105 horas, constitui a última etapa das 315 horas exigidas pelo curso.

A tendência na formação de professores abordada - recortando o estágio curricular supervisionado, pressupõe articulação sistêmica, noções centrais de sujeito, de diálogo, de conhecimento. As dimensões teóricas e práticas pressupõem uma abordagem reflexiva, de natureza construtivista que, ao desafio de implementação de um currículo com tais características, impõe-se a necessidade de construção de um novo paradigma para o estágio curricular supervisionado, em que as tecnologias da informação e da comunicação perpassam a abrangência da formação pedagógica do futuro professor. O Curso, embora presencial, utiliza o Ambiente Moodle, como suporte para ensino e aprendizagem das disciplinas da grade curricular, procurando, no Estágio 
Supervisionado III, utilizar os recursos tecnológicos disponíveis, em especial a Wiki, que proporciona um importante processo de interação, necessário para a abordagem formativa, norteadora deste estudo de investigação.

Retornando ao pensamento de Schön, presente em Alarcão (2000), tal abordagem entende o conhecimento profissional em seu contexto e sistematizado em uma dinâmica interativa entre a ação e o pensamento ou a reflexão. É, antes de tudo, uma prática que deve expressar o poder de reconstrução social (LIMA, 2002). A ferramenta wiki constitui-se, portanto, em um recurso tecnológico-metodológico capaz de suportar as redes conversacionais que povoam um ambiente e o torna um espaço de ensino e aprendizagem, em que a construção do conhecimento se faz pela reflexão da ação, gerando, desta forma, mudanças de conduta, tanto pessoais como profissionais, registrando indicadores para o processo avaliativo das competências pertinentes ao estágio.

Sendo assim, a proposta para os alunos estagiários baseia-se, entre outras coisas, na postagem dos planos de aula, através desta ferramenta. Antes de cada aula a ser ministrada, os estudantes devem postar o tema da aula, objetivo(s), metodologia, avaliação (se for o caso), bibliografia, enfim, um planejamento para o tempo da sua aula. O professor da UFSM, por sua vez, deve orientar o aluno, sempre que necessário, visando a metodologia adequada, uso de recursos tecnológicos e didáticos. Posteriormente, o estagiário pode fazer uma análise da implementação, ou seja, um relato sobre como foi a execução do seu planejamento e, a partir disso, fazer a reflexão de sua ação. Nesta, o aluno-professor deve refletir sobre a sua atuação, abordando os pontos positivos, aspectos que podem ser melhorados e as contribuições cognitivas que a experiência lhe trouxe.

Tais registros são entendidos como escrita autobiográfica, os quais podem ser utilizados como instrumento para identificar o desenvolvimento das competências, quando se trabalha com adultos (RELA, 2010). O elemento de input é a escrita do plano de aula, que deve descrever a ação prevista para a atuação em campo. Essa produção dá início a um processo de investigação sobre a experiência do sujeito, uma vez que reflete conceitos, estruturas e competências a serem operadas na ação. $\mathrm{O}$ orientador procederá à heteroavaliação, que procura identificar e/ou certificar o nível de adequação dos recursos e das habilidades de um sujeito em relação a um específico, ou possível, âmbito de atividade, para auxiliar na promoção de níveis sempre maiores de consciência sobre suas capacidades.

Outra produção autobiográfica é os registros de autoria com descrição e análise das experiências do sujeito no campo de estágio. Os processos de narração poderão implicar - além do fato de objetivarem-se em uma autobiografia - a exteriorização da experiência dos professores. Tais processos oferecem ocasiões de análise e de reflexão sobre eventos do ensinar: a experiência se torna texto que solicita sua interpretação. E cada ato interpretativo comporta uma atribuição de significado deixando o registro de indicadores para a avaliação. 
Os pesquisadores (que são professores formadores que atuam no curso citado) acreditam que esse é um dos momentos significativos da orientação, pois é neste escopo que ambos - professor e aluno - constituem uma rede de coordenações de ações num domínio de aceitação mútua. A rede de conversação emerge na medida em que as pessoas começam a se comunicar, a conversar, e o conversar, neste espaço, é realizado através de recursos capazes de dar suporte à comunicação, como a ferramenta wiki, correio eletrônico, fórum (ROCHA, 2008). O uso da ferramenta wiki foi a hipótese de trabalho, estabelecida como tentativa de construção de um espaço efetivo para o registro autoral das reflexões realizadas, as produções sistematizadas, passando a ser, também, o campo de observação e análise da categorização de indicadores para a supervisão de estágio e a prática pedagógica.

O processo das interações interindividuais foi constantemente alimentado pelos registros do professor orientador que, a cada planejamento de aula, deixava suas contribuições na wiki. A cada feedback, o professor escrevia refletindo sobre o processo percebido e fazendo as considerações pertinentes. $\mathrm{O}$ espaço de interação individual, ou seja, entre professor e aluno, tornou-se, aos poucos, povoado pelas reflexões registradas, em que foi possível mapear o processo individual acerca da relação teoria e prática, estendendo-se para uma maior abrangência. Ao final do semestre, os registros possibilitaram resgatar o processo de reflexão, as mudanças de conduta, tomada de decisões, construções conceituais, evidência de concepções de cada estagiário de forma a estimular um processo metacognitivo. Esta ação contribui para que o sujeito aprendente se torne cada vez mais capaz de colher indícios, de atingir níveis de complexidade na interpretação de seus significados e de incorporá-los como eventos relevantes para a dinâmica do ensino e aprendizagem/metacognição.

Para a organização deste trabalho, optou-se pela configuração de uma atividade wiki no modo individual. $\mathrm{O}$ "modo wiki" determina se todo mundo pode editar a wiki (colaborativa), ou se cada um tem sua própria wiki, a qual somente o estudante e o professor orientador podem editar (individual). A opção pelo modo individual justifica-se pelo fato que cada estudante precisa fazer seus planejamentos e relatos das aulas implementadas, uma vez que o estágio supervisionado é uma atividade individual. Além disso, deixa o estudante mais à vontade para fazer suas análises e reflexões pois, além dele, apenas o professor, que tem papel de orientar, tem acesso aos relatos.

Desta forma, a primeira fase dos apontamentos, como já mencionado, caracterizou-se pelas postagens do planejamento de cada aula, em que o aluno deveria expor, claramente, todos os momentos pedagógicos para desenvolver o conteúdo previsto. A fase posterior - o relato da implementação - compôs, juntamente, a estrutura da rede de dados coletados para a pesquisa, possibilitando, assim, a análise através de seis categorias emergentes dos apontamentos realizados e com base nos estudos desenvolvidos por Bassani (2009). Portanto, identificamos as categorias: indagação (questionamentos/investigação); argumentação (chamar a discussão); reflexão (pensamento sobre a própria atuação). Estas, nortearam tanto os Planos de Aula como os Relatos da implementação, por parte da orientação e pelo aluno estagiário. Como cada orientador possuía um grupo de alunos (17 e 12), a análise abrangeu 29 unidades de registro, coletadas durante o primeiro semestre de 2012, Desta forma, a metodolo- 
gia de pesquisa envolveu três momentos: análise do conteúdo das mensagens, através das categorias; agrupamento das análises e análise das contribuições das interações/ reflexões, mediados pela ferramenta wiki, para a formação do professor reflexivo, da Educação Profissional.

\section{Apresentação e análises dos resultados}

Para analisar o conteúdo das mensagens, cada unidade de registro foi classificada de acordo com as categorias predominantes, ou seja, a partir das postagens, na ferramenta wiki, foi feito uma análise detalhada de todos os Planos de Aula e Relatos de cada aluno, identificando as categorias emergentes, conforme os exemplos.

Exemplo de Plano de Aula:

$\mathrm{O}$ aluno postava o planejamento com antecedência de quinze dias a uma semana da data de implementação da aula. Os Planos de Aula seguiam metodologias variadas mas, em sua maioria estavam organizados em três Momentos Pedagógicos - MP (ABEGG; DE BASTOS, 2005), visto que era um dos modelos trabalhados nas disciplinas do currículo do curso. Assim, após a postagem pelo aluno, o professor acessa a wiki e faz suas orientações ao longo do texto em letras de cor diferente para melhor visualização das alterações/orientações. Cada professor tinha sua dinâmica, mas o professor da turma deste exemplo utilizava cores com significados diferentes (verde, quando estava tudo Ok e o planejamento estava aprovado; amarelo, quando fazia observações que não, necessariamente, precisam ser contempladas e, em vermelho, quando o planejamento precisava ser modificado. No Plano de Aula deste exemplo, havia necessidade de alterações:

Data: $12 / 05 / 2012$

Tema: continuação do Sistema Cardiovascular (SCV)

Objetivos: Concluir o assunto iniciado na aula anterior com ênfase ao aprendizado das principais veias e artérias que irrigam o coração.

Correlacionar a anatomia e fisiologia com algumas condições patológicas do SCV.

10 MP: Retomada do conteúdo da aula anterior (Iniciar questionando sobre a aula prática) $(50 \mathrm{~min})$.

20 MP: Serão abordadas patologias do SCV previamente disponibilizadas aos alunos por meio de xerox $(50 \mathrm{~min})$.

3० MP:[....]

Ok, [aluno 4]. No $1^{\circ} \mathrm{MP}$ (Momento Pedagógico) faltaram as questões que irá fazer aos estudantes. Afinal o que você vai questionar/problematizar? No mais a aula está bem organizada.

Após estas Indagações/orientações, o aluno fez as alterações, modificando o planejamento e o $1^{\circ} \mathrm{MP}$ ficou assim:

1 MP: Retomada do conteúdo da aula anterior (Iniciar questionando sobre a aula prática): "Qual a diferença entre artérias e veias vistas na aula prá- 
tica?" (Será explicado o conteúdo disponibilizado na apostila e através de uma atividade dinâmica com a participação dos alunos demonstrar como ocorre a pequena e a grande circulação $(50 \mathrm{~min}$.).

$2^{\circ} \mathrm{MP}:[\ldots]$

Portanto, com estas alterações, o estagiário pode fazer uma reflexão sobre os objetivos e quais os conteúdos que iria priorizar em sua próxima aula. Ao deixar o 1` MP mais "completo", com informações mais claras sobre o que iria desenvolver na aula, ele ficou também mais preparado, do ponto de vista da argumentação, para o diálogo com seus estudantes. Isso ficou demonstrado no relato da implementação, no qual o estagiário destacou que o questionamento inicial foi essencial para o sucesso da aula. Este exemplo nos indica, portanto, a ocorrência das categorias Indagação, Argumentação, Reflexão.

Exemplo de Relato da Implementação:

Data: 25/06/2012

Tema da Aula: Relações interpessoais no trabalho

Objetivos: Estudar sobre os fatores interpessoais e a qualidade de vida no trabalho; realizar uma dinâmica, visando a interação e comunicação entre o grupo

[...] Continuamos o conteúdo e em seguida o sinal para o intervalo tocou. Quando retornamos, continuamos a aula com as cadeiras em círculo. Gostei desta forma de organizar a sala, pois todos poderiam se olhar e interagir mais. Próximo ao término da aula utilizei uma estratégia nova em sala de aula. Pedi que os alunos pudessem escrever em no mínimo um parágrafo o que eles aprenderam daquela aula. A medida que eles foram entregando, fui lendo o que eles traziam. Era muito interessante, pois a aula foi a mesma para todos, no entanto, cada um trouxe um fragmento diferente daquela aula. Foi um feedback interessante para mim enquanto professora. Oi [Aluno 11], muito boa atividade. De acordo com o relato dos alunos, ela ajudou nas relações interpessoais?

flexões:

Após esta Reflexão e Indagação, o aluno fez as argumentações e novas re-

Oi Profa. Segundo os alunos a dinâmica ajudou no entendimento do conteúdo. Mas honestamente, nesta dinâmica, senti que ajudou também para descontrair a turma. Os senti cansados (a grande maioria dos alunos trabalha de dia e estuda à noite, e certos dias, entendo que eles estejam mais cansados) e percebi que essa atividade os animou e os integrou ainda mais. Claro que cabe a mim enquanto professora sempre reforçar qual a intencionalidade em realizar tais dinâmicas, para que esta cumpra seus objetivos e para que os alunos possam percebê-las como uma forma de relacionar a teoria com a prática.

O exemplo desse Relato indica a ocorrência das categorias Reflexão e Indagação, Argumentação, o que nos faz pensar na confirmação da ação-reflexão-ação. 
Assim, para o agrupamento das análises, cada unidade de registro foi classificada de acordo com as categorias predominantes, ou seja, a partir das postagens, na ferramenta wiki, foi feito uma análise detalhada de todos os Planos de Aula e Relatos de cada aluno e identificado, em uma tabela (exemplo Tabela 01), a ocorrência de Indagações, Argumentações e Reflexões, tanto no P.A. (Plano de Aula), quanto no R.I. (relato da Implementação).

Tabela 1: Modelo para Análise dos Planos de Aula e Relatos das Implementações, através das categorias emergentes.

\begin{tabular}{|c|c|c|c|c|c|c|}
\hline Aluno & P.A. Indag. & $\begin{array}{c}\text { P.A. } \\
\text { Argum. }\end{array}$ & P.A. Refl. & R.I. Indag. & $\begin{array}{c}\text { R.I. } \\
\text { Argum. }\end{array}$ & R.I. Refl. \\
\hline 1 & $\mathrm{x}$ & & $\mathrm{x}$ & & $\mathrm{x}$ & $\mathrm{x}$ \\
\hline 2 & $\mathrm{x}$ & $\mathrm{x}$ & $\mathrm{x}$ & $\mathrm{x}$ & $\mathrm{x}$ & $\mathrm{x}$ \\
\hline Total & 02 & 01 & 02 & 01 & 02 & 02 \\
\hline
\end{tabular}

Como foram analisados dois casos (duas turmas), os resultados desta categorização apontam os seguintes resultados:

a) Turma A: 17 alunos (17 wikis) analisados: 10 indagações, 07 argumentações e 13 reflexões referentes aos Planos de Aula; 05 indagações, 11 argumentações e 16 reflexões referentes aos Relatos das Implementações dos Planos de Aula.

a) Turma B: 12 alunos (12 wikis) analisados: 07 indagações, 07 argumentações e 08 reflexões referentes aos Planos de Aula; 06 indagações, 06 argumentações e 11 reflexões referentes aos Relatos das Implementações dos Planos de Aula.

Podemos perceber, de acordo com os exemplos, que as mensagens não se enquadram apenas em uma categoria, ao contrário, se entrelaçam num ir e vir, que nos permite pensar na confirmação da reflexão sobre a ação de ambos os atores, na medida em que o "dar voltas juntos" abrange as indagações, que geram argumentações, que instigam reflexões, que, por sua vez, podem ou não serem aceitas, mas que convergem para um único objetivo: a formação de um professor reflexivo, a partir desta proposta de orientação. Portanto, a partir destas experiências, podemos analisar as contribuições que a ferramenta wiki pode proporcionar à ação-reflexão-ação em rede, corroborando com a formação do docente da Educação Profissional e com o processo de registro dos indicadores para o desenvolvimento das competências necessárias ao estágio.

\section{Das conclusões temporárias}

O propósito deste artigo foi problematizar uma vivência de estágio, em um programa de formação de professores para a educação profissional, utilizando as novas tecnologias como apoio à prática docente e à avaliação.

A luz dos conceitos de (inter)ação, reflexão sobre a reflexão na ação, aprendizagem, avaliação, pudemos observar os registros, apontamentos, reflexões realizadas através da ferramenta wiki, muitas vezes identificadas nos meandros subjetivos das 
conversas. Percebemos, a partir desta investigação, que as tecnologias educacionais em rede podem constituir-se importantes espaços de reflexão, que conduzem mudanças significativas na ação, ampliando ou restringindo as interações, de acordo com o posicionamento de cada ator. O registro dos Planos de Aula e sua implementação, os feedback no espaço wiki, por parte dos orientadores e estagiários, proporcionaram categorias de elementos indicadores para a orientação dos futuros estágios, na forma de rede de conversação, revelando, assim, a possibilidade de acompanhamentos, orientações e avaliações das aprendizagens e dos processos de reconstrução, resignificação da ação dos sujeitos aprendentes.

Observou-se o inicio de uma apropriação reflexiva, pelos futuros docentes, da necessidade e importância da inserção dos recursos disponíveis das tecnologias educacionais em rede, na proposta pedagógica, indo, portanto, ao encontro com as Diretrizes Curriculares Nacionais vigentes. Apoiada pelos pressupostos da aprendizagem colaborativa, através de um ambiente virtual de ensino e aprendizagem, a proposta de orientação permite aos sujeitos aprendentes (professor e aluno) a autogeração, autoprodução do conhecimento.

A autogeração é uma rede de processos de produção, nos quais a função de cada componente consiste em participar da produção ou da transformação de outros componentes da rede. Deste modo, toda a rede, continuamente, produz a si mesma. Ela é produzida pelos seus componentes e, por sua vez, produz esses componentes. Num sistema vivo, o produto de sua operação é a sua própria organização. (CAPRA, 2006, p. 89).

Entre os pontos positivos, destacou-se a construção de conhecimentos, uma vez que o registrar, refletir, reavaliar levou ao amadurecimento do profissional docente e aprimoramento das competências. Outro ponto positivo foram os instrumentos autobiográficos, os quais colocaram o sujeito como foco central do processo da avaliação. O tempo de estágio tornou-se, efetivamente, um período de construção de experiências, para além do espaço acadêmico. Período este que possibilitou a identificação dos pressupostos: reciprocidade entre os atores sociais; feedback entre consorciados; encorajamento à tomada de consciência das competências; cooperação em rede e por meio da rede; experiência docente como lócus da avaliação; e instrumento comum para acompanhamento das evidências do processo de construção das competências.

\section{Referências}

ABEGG, I. ET AL. Estágio Supervisionado de Ensino mediado pelo wiki do Moodle. Projeto de Pesquisa GAP/CE no 033655. Universidade Federal de Santa Maria. Centro de Educação. 2013.

ABEGG, I.; DE BASTOS, F. da P. Fundamentos para uma prática de ensino-investigativa em Ciências Naturais e suas tecnologias: exemplar de uma experiência em séries iniciais. Revista Electrónica de Enseñanza de las Ciencias.v. 4, n. 3, 2005.

ALBERICI, A. La possibilita di cambiare: aprendere a aprendere come risorsa strategica per la vita. Milano: Franco Angeli, 2008.

ALARCÃO, I. Escola Reflexiva e Supervisão. Porto: Porto Editora, 2000. 
CAPRA, F. A teia da vida. São Paulo: Cultrix, 2006.

FREIRE, P. et al. Pedagogia: diálogo e conflito. 4. ed. São Paulo: Cortez, 1995.

Pedagogia da autonomia: saberes necessários à prática educativa. São Paulo: Editora Paz e Terra, 1986.

LIMA, M. do S. L. Redimensionando o Papel dos Profissionais da Educação: algumas considerações. In: Selma Garrido Pimenta, Evandro Ghedin (Org.). Professor reflexivo no Brasil: gênese e critica de um conceito. São Paulo: Cortez. 2002.

MATURANA, H. A ontologia da realidade. Belo Horizonte: Editora UFMG, 2002

MORIN, E. Ciência com consciência. Rio de Janeiro: Bertrand Brasil, 2005.

PIMENTA, S. G.; LIMA, M. S. L. Estágio e docência. 5. ed. São Paulo: Cortez, 2010.

RELA, E. Avaliação no estágio supervisionado: intersubjetividades na formação de professores em cursos na modalidade EAD/Eliana Rela; orientador: Profa. Dra. Marie Jane Soares Carvalho; Tese (Doutorado) - UFRGS- PPGIE, 2010, Porto Alegre, BR.

RELA, E.; ROCHA, K. M. da; GOULART, M. B.; CARVALHO, M. J. S. de. Estágio em Rede: a cooperação na prática docente. In: XVII SIMPÓSIO BRASILEIRO DE INFORMÁTICA NA EDUCAÇÃO, 2006, Brasília. XVII Simpósio Brasileiro de Informática na Educação, 2006.

Resolução CNP/CP 1, de 18 de Fevereiro de 2002. Disponível em: <http://portal.mec.gov.br/ seesp/arquivos/pdf/res1_a.pdf> Acesso em: 8 out. 2006.

ROCHA, K. M. da. Estudo sobre a constituição de um sistema social em ambiente virtual de aprendizagem. Porto Alegre: UFRGS, 2008. Tese (Doutorado em Informática na Educação), Centro Interdisciplinar de Novas Tecnologias na Educação, 2008.

SCHÖN, D. Formar professores como profissionais reflexivos. In: NÓVOA, A. (Org.). Os professores e sua formação. Lisboa: Dom Quixote, 1992.

SCHONS, C. H. (2008). A contribuição dos Wikis como ferramentas de colaboração no suporte à gestão do conhecimento organizacional. Inf. \& Soc.: Est., João Pessoa, v.1 8, n. 2, p. 79-91, maio/ago. 2008. Disponível em: <http://www.ies.ufpb.br/ojs2/index.php/ies/article/ view/1706>. Acesso em: 04 mai. 2011.

SILVA, M. Interatividade: uma mudança fundamental do esquema clássico da comunicação. In: COMPÓS: ENCONTRO NACIONAL DA ASSOCIAÇÃO NACIONAL DOS PROGRAMAS DE PÓS-GRADUAÇÃO EM COMUNICAÇÂO, 9., 2002, Porto Alegre. Anais. Porto Alegre: PUCRS, 2002. p.125-138.

TAPSCOTT, D.; WILLIAMS, A. D. (2007). Wikinomics: como a colaboração em massa pode mudar o seu negócio. Tradução Marcello Lino. Rio de Janeiro: Nova Fronteira, 2007.

VIEIRA, A. Humberto Maturana e o Espaço Relacional da Construção do Conhecimento. Educação e Humanidades. Brasília, v. 1, n. 2, p. 1-6, nov. 2004. Disponível em: <http://www. humanitates.ucb.br/2/maturana.htm >. Acesso em: 03 maio 2012.

ZITKOSKI, J.J. Diálogo/Dialogicidade. In: STRECK, D. R.; REDIN, e (Orgs.). Dicionário Paulo Freire. Belo Horizonte: Autêntica Editora, 2008. 
* Professora Doutora da Universidade Federal de Santa Maria, Santa Maria, Rio Grande do Sul, Brasil.

** Professora Doutora da Universidade Federal de Santa Maria, Santa Maria, Rio Grande do Sul, Brasil.

*** Professora Doutora da Universidade de Caxias do Sul, Caxias do Sul, Rio Grande do Sul, Brasil.

\section{Correspondência}

Karla Marques da Rocha - Universidade Federal de Santa Maria, Av. Roraima, 1000, Campus Universitário. CEP: 97105-900 - Santa Maria, Rio Grande do Sul, Brasil.

E-mail: karlamarquesdarocha@gmail.com - ilse.abegg@ufsm.br - erela@ucs.br

Recebido em 29 de abril de 2014

Aprovado em 09 de outubro de 2014 
